\title{
The Elevation of Annals of Rehabilitation Medicine to the Status of an International Journal After Adopting an English-Only Policy
}

\author{
Sun Huh, MD
}

Department of Parasitology and Institute of Medical Education, Hallym University College of Medicine, Chuncheon, Korea

Objective To use bibliometric analyses to determine whether Annals of Rehabilitation Medicine (hereafter also referred to as Annals) became an international journal after adopting an English-only policy in 2011.

Methods Articles from the third issue of 2011 to the third issue of 2015 were analyzed according to the following parameters: whether the research was supported by funding, country of authorship, impact factor, total citations, the countries of researchers who cited Annals; the journals that cited Annals; and the Hirsch index.

Results One hundred twenty-eight (34.2\%) of the 374 original articles were supported by research funds. The main authors were from Korea (550/556, 98.9\%), the USA (3), Iran (2), Japan (1), Turkey (1), and the United Kingdom (1). The manually calculated impact factors in 2013 and 2014 were 0.582 and 0.667 , respectively. The total annual citations from years 2012 to 2015 were 15, 130, 252, and 189, respectively. The countries of residence of the main authors who cited Annals were the USA (146), Korea (89), and China (49). The journals that cited Annals most frequently were the Journal of Physical Therapy (34), Archives of Physical Medicine and Rehabilitation (15), and Frontiers in Human Neuroscience (13). The Hirsch index was 9.

Conclusion The above results demonstrate that the change of the language policy of Annals to English-only was successful in elevating the journal to the international level. The journal's aim of sharing up-to-date knowledge dedicated to advancing the care of the disabled and enhancing their everyday abilities and quality of life has been satisfactorily realized.

Keywords Bibliometrics, Journal impact factor, Periodicals

Received August 17, 2015; Accepted August 28, 2015

Corresponding author: Sun Huh

Department of Parasitology and Institute of Medical Education, Hallym University College of Medicine, 1 Hallimdaehak-gil, Chuncheon 24252, Korea

Tel: +82-33-248-2652, Fax: +82-33-241-1672, E-mail: shuh@hallym.ac.kr

(c) This is an open-access article distributed under the terms of the Creative Commons Attribution Non-Commercial License (http://creativecommons. org/licenses/by-nc/4.0) which permits unrestricted noncommercial use, distribution, and reproduction in any medium, provided the original work is properly cited.

Copyright $\odot 2015$ by Korean Academy of Rehabilitation Medicine

\section{INTRODUCTION}

From 1977 to 2011, the Korean Academy of Rehabilitation Medicine published an official journal entitled the Journal of Korean Academy of Rehabilitation Medicine. A new editorial vision emerged, with the goal of widening the readership and authorship of the journal throughout the Asia-Pacific region. Therefore, starting in the third issue of 2011, the Society changed the journal's name to Annals of Rehabilitation Medicine and instituted an 
English-only policy. This study examines whether Annals of Rehabilitation Medicine has become an internationallevel journal based on an analysis of journal metrics that have been widely used for journal evaluation $[1,2]$. This study also attempts to characterize the position of Annals in the international journal network.

\section{MATERIALS AND METHODS}

Articles from the third issue of 2011 to the third issue of 2015 were included in our analysis. The number of citable and non-citable articles was counted. The proportion of original articles that were supported by research funds was calculated. Authors' countries were counted. The impact factor was manually calculated based on data from the Web of Science, and was compared with the impact factor of other Science Citation Index-Expanded journals included in the Journal Citation Ranking (JCR). For example, the 2013 impact factor was calculated as follows:

Number of citable articles published in Annals of Rehabilitation Medicine in 2011: A

Number of citable articles published in Annals of Rehabilitation Medicine in 2012: $\mathrm{B}$

Frequency of citations of 2011 articles from Annals of Rehabilitation Medicine in articles published in 2013 and indexed in the Web of Science: $\mathrm{C}$

Frequency of citations of 2012 articles from Annals of Rehabilitation Medicine in articles published in 2013 and indexed in the Web of Science: D

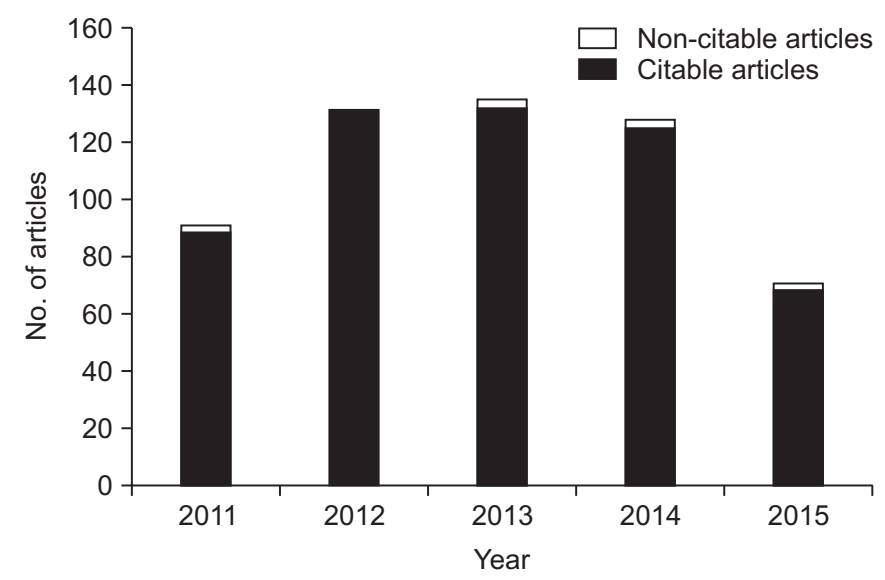

Fig. 1. The number of citable and non-citable articles in Annals of Rehabilitation Medicine according to year [as of August 8, 2015].
2013 impact factor of Annals of Rehabilitation Medicine = $(C+D) /(A+B)$

The total number of citations in the Web of Science was determined. The countries of the citing authors, the source journals of the citations, and the Hirsch index were analyzed. The Hirsch index of a journal is defined as the number of papers with a citation number of $h$. This definition is an extension of the original definition of the Hirsch index for individual researchers: ' $A$ ' scientist has index $h$ [the Hirsch number] if $h$ of his or her $N_{\mathrm{p}}$ [number of published] papers have at least $h$ citations each and the other $\left(N_{p}-h\right)$ papers have equal to or less than $h$ citations each [1]. The Hirsch index was suggested originally for the evaluation of an individual researcher's publication activities; however, the concept was extended to the evaluation of a journal's or institution's publishing activities. All data analyses were performed on August 8, 2015.

\section{RESULTS}

The number of articles by year is presented in Fig. 1 . Out of 556 articles, 10 were non-citable. The annual proportions of original articles that were supported by research funds from 2011 to 2015 were $24.6 \%, 31.8 \%, 36.6 \%$, $39.5 \%$, and $38.8 \%$, respectively (Fig. 2). The authors were from Korea (550/556 articles), the USA (3), Iran (2), Japan (1), Turkey (1), and the United Kingdom (1) (Fig. 3). The manually calculated impact factor for 2013 was 0.582 , which was the 58th highest value of the 63 journals in the category of rehabilitation in the 2013 JCR. The im-

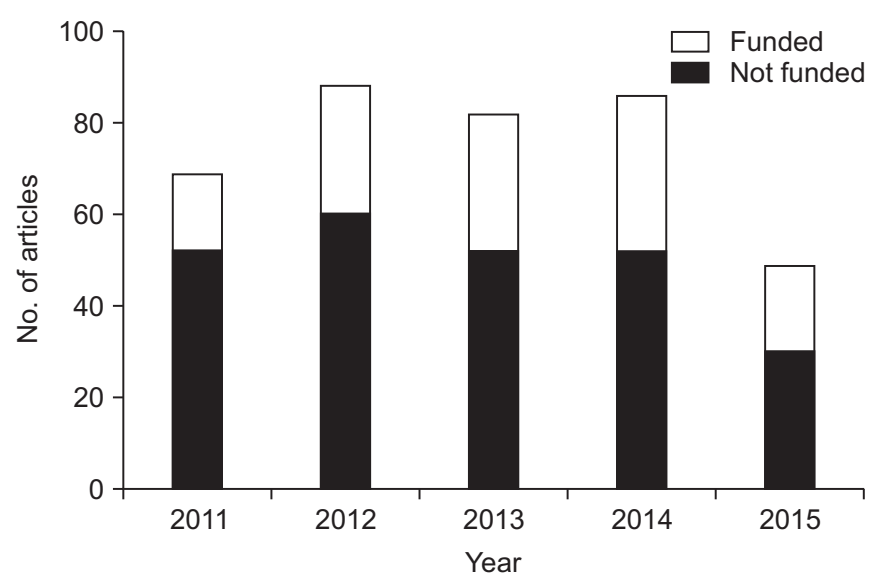

Fig. 2. The number of original articles in Annals of Rehabilitation Medicine supported by research funding according to year. 


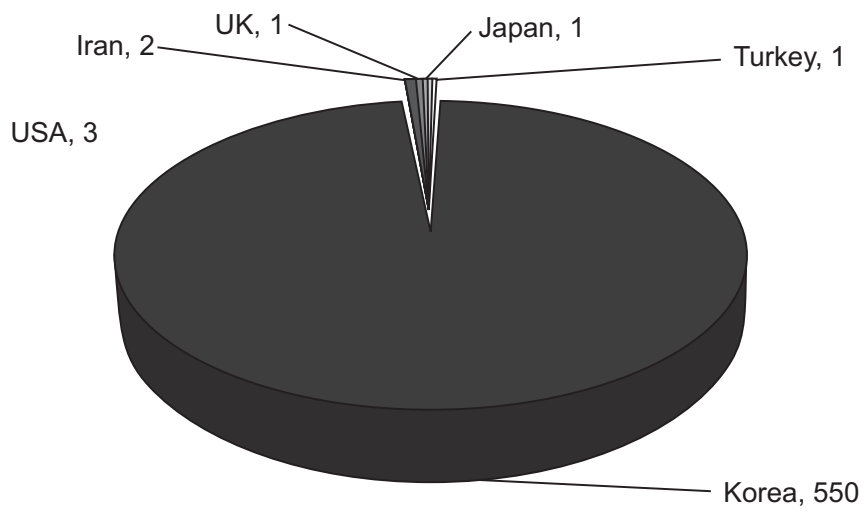

Fig. 3. The countries of the authors of articles in Annals of Rehabilitation Medicine from 2011 to June 2015.

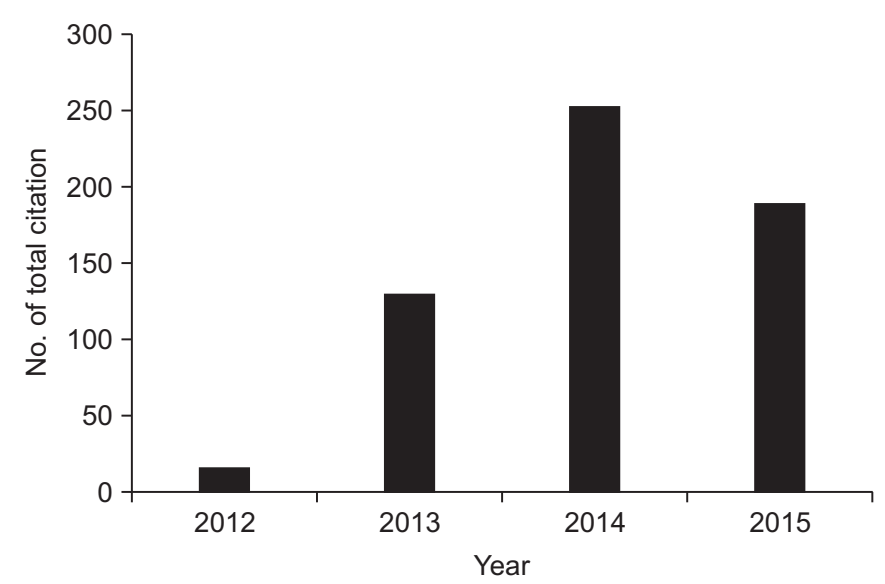

Fig. 4. The number of total citations of articles in Annals of Rehabilitation Medicine from the Web of Science according to year [as of August 8, 2015].

pact factor in 2014 was 0.667 , which was the 55th highest value of the 64 journals included in the 2014 JCR. A total of 261 of the 546 citable articles $(47.8 \%$ ) were cited at least one time by articles in the Web of Science. The total annual citations from years 2012 to 2015 were 15, 130, 252, and 189, respectively (Fig. 4). The countries of the citing authors are shown in Fig. 5. The USA was the top-ranking country, followed by Korea and China. Annals of Rehabilitation Medicine has been cited by articles in 99 journals. The journals that most frequently cited Annals of Rehabilitation Medicine were: Journal of Physical Therapy Science (34), Archives of Physical Medicine and Rehabilitation (15), Frontiers in Human Neuroscience (13), and NeuroRehabilitation (12) (Fig. 6). All but one journal that frequently cited Annals were classified as rehabilitation journals. The Hirsch index was 9 (Table 1).

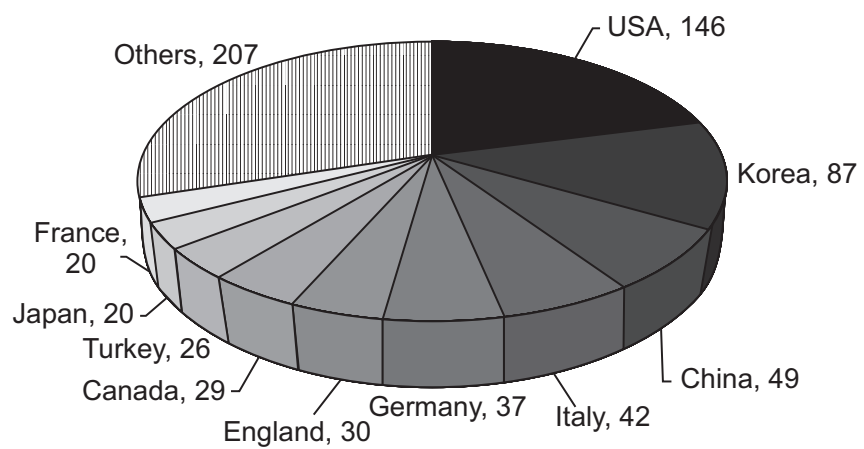

Fig. 5. The countries of authors who cited Annals of Rehabilitation Medicine in articles included in the Web of Science [as of August 8, 2015].

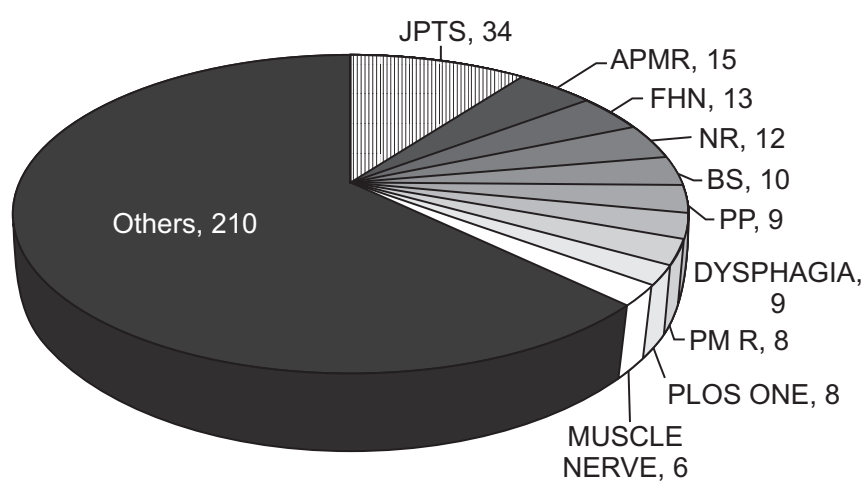

Fig. 6. The titles of journals that cited Annals of Rehabilitation Medicine in articles included in the Web of Science [as of August 8, 2015]. JPTS, Journal of Physical Therapy Science; APMR, Archives of Physical Medicine and Rehabilitation; FHN, Frontiers in Human Neuroscience; NR, NeuroRehabilitation; BS, Brain Stimulation; PP, Pain Physician.

\section{DISCUSSION}

After changing the title of the journal and adopting an English-only policy, the international profile of Annals of Rehabilitation Medicine rose dramatically. The impact factor and total number of citations increased rapidly. The frequent citations of articles published in Annals of Rehabilitation Medicine may have been due to the openaccess policy of the journal and the inclusion of Annals in PubMed Central (PMC) and PubMed starting in April 2012. Since PubMed and PMC are the most frequently accessed databases for medical researchers and physicians, biomedical journals must be included in those databases in order to ensure wide propagation of their content. In order to be included in PMC, a journal must have an 
Table 1. The Hirsch index of Annals of Rehabilitation Medicine from the Web of Science as of August 8, 2015

\begin{tabular}{|c|c|c|c|c|c|c|}
\hline Ranking & Title & Year & Vol & Issue & $\begin{array}{l}\text { Starting } \\
\text { page }\end{array}$ & $\begin{array}{l}\text { No. of } \\
\text { citations }\end{array}$ \\
\hline 1 & $\begin{array}{l}\text { Suppression of seizure by cathodal transcranial direct current stimu- } \\
\text { lation in an epileptic patient: a case report }\end{array}$ & 2011 & 35 & 4 & 579 & 14 \\
\hline 2 & $\begin{array}{l}\text { Improvement of the working memory and naming by transcranial di- } \\
\text { rect current stimulation }\end{array}$ & 2012 & 36 & 5 & 585 & 14 \\
\hline 3 & $\begin{array}{l}\text { The effect of virtual reality training on unilateral spatial neglect in } \\
\text { stroke patients }\end{array}$ & 2011 & 35 & 3 & 309 & 12 \\
\hline 4 & $\begin{array}{l}\text { The factors associated with good responses to speech therapy com- } \\
\text { bined with transcranial direct current stimulation in post-stroke } \\
\text { aphasic patients }\end{array}$ & 2011 & 35 & 4 & 460 & 12 \\
\hline 5 & $\begin{array}{l}\text { The effect of the forward head posture on postural balance in long } \\
\text { time computer based worker }\end{array}$ & 2012 & 36 & 1 & 98 & 12 \\
\hline 6 & $\begin{array}{l}\text { Spasticity and electrophysiologic changes after extracorporeal shock } \\
\text { wave therapy on gastrocnemius }\end{array}$ & 2011 & 35 & 5 & 599 & 10 \\
\hline 7 & $\begin{array}{l}\text { Ultrasonography of median nerve and electrophysiologic severity in } \\
\text { carpal tunnel syndrome }\end{array}$ & 2012 & 36 & 1 & 72 & 10 \\
\hline 8 & $\begin{array}{l}\text { Kambin's triangle approach of lumbar transforaminal epidural injec- } \\
\text { tion with spinal stenosis }\end{array}$ & 2011 & 35 & 6 & 833 & 9 \\
\hline 9 & $\begin{array}{l}\text { The Effects of intra-articular platelet-rich plasma injection according } \\
\text { to the severity of collagenase-induced knee osteoarthritis in a rab- } \\
\text { bit model }\end{array}$ & 2012 & 36 & 4 & 458 & 9 \\
\hline
\end{tabular}

English-only policy, as well as an open-access policy or a public-access policy with an embargo period. Moreover, the PMC eXtensible Markup Language (XML) files of all articles must be deposited in the database. Many medical journals in Korea began to produce PMC XML files starting in 2007, and such journals have been indexed in PMC since 2008. A major advantage of PMC journals is that their citation XML is automatically transferred from PMC XML to PubMed. Therefore, the editors of major medical journals in Korea began to adopt English-only policies and to produce PMC XML files, which have recently been changed to Journal Article Tag Suite (JATS) XML files [2,3]. The production of PMC XML files starting in 2007 and their subsequent inclusion in PMC was a turning point for many Korean medical journals because their impact was previously underestimated due to the absence of citation information in the PubMed database. Before 2007, only 16 biomedical journals from Korea were indexed in Medline/PubMed, according to the United Sates National Library of Medicine Catalog available from: http://www. ncbi.nlm.nih.gov/nlmcatalog/journals. The PMC project launched in 2000 by the National Library of Medicine became a driving force for the internationalization of Ko- rean medical journals. Annals successfully adapted itself to this new environment of internationalization, as demonstrated by the fact that its citation frequency soared after being indexed in PMC [4].

Most citations of articles published in Annals were from the USA. This result is not surprising, because the large number of articles in the field of rehabilitation medicine is published by authors from the USA. Additionally, rehabilitation physicians and researchers in the USA may have common interests with researchers in Korea. The frequency of citations by Chinese researchers may be explained by the presence of common patterns of disease in Chinese and Korean populations. Since most journals that cited Annals were classified as rehabilitation journals, Annals was empirically shown to also be a rehabilitation journal.

The most frequently cited pieces were original articles, with only one exception among the top nine articles (Table 1). The top-ranking two articles, cited 14 times each, were a case report and an original article. This pattern is inconsistent with what has been observed in other journals, in which review articles and original articles are the most frequently cited publication types [5-7]. Annals 
was different because it has published only one review article in the past four years. Moreover, a score of 9 on the Hirsch index is astonishing. The Hirsch indices of the following Korean journals have been reported: Clinical Endoscopy, which began English-language publication in 2011, had a Hirsch index of 6 [5]; the Korean Journal of Urology, which has been published since 1960, had a Hirsch index of 11 [6]; Clinical and Experimental Reproductive Medicine, which has been published in English since 2011, had a Hirsch index of 6 [7]; Archives of Plastic Surgery, which initiated an English-language policy in 2012, had a Hirsch index of 6 [8]; Diabetes \& Metabolism Journal, which adopted an English-only policy in 2010, had a Hirsch index of 9 [9]; International Neurourology Journal, which adopted an English-only policy in 2010, had a Hirsch index of 6 [10]; and the Korean Journal of Internal Medicine, which has had an English-only policy since 1987, had a Hirsch index of 15 [11].

In 2013, CrossMark, FundRef, and the Open Researcher and Contributor ID (ORCID) were introduced to Korean medical journals [12]. CrossMark is used to identify the most recent version of an article, FundRef is a project that establishes unique IDs for funding organizations, and ORCID is a system establishing unique IDs for researchers. It is not difficult to integrate these additional services into a journal, since the process can be accomplished using a conversion program that works with JATS XML files $[13,14]$. The above services should be added to Annals as soon as possible, in order to catch up with international standards. Moreover, CrossRef text and data mining services should be included in Annals [15].

In conclusion, according to the above bibliometric findings, after adopting an English-only policy in 2011, Annals of Rehabilitation Medicine has succeeded in converting to an internationally acceptable format and attaining a level of quality worthy of international recognition. The adoption of an open-access policy has helped immensely to propagate valuable findings in the field of rehabilitation medicine. In the near future, it will be possible for Annals to continue to raise its profile in the field of rehabilitation medicine.

\section{CONFLICT OF INTEREST}

No potential conflict of interest relevant to this article was reported.

\section{ACKNOWLEDGMENTS}

This work was supported by the Hallym University Research Fund (HRF-G-2015-4).

\section{REFERENCES}

1. Hirsch JE. An index to quantify an individual's scientific research output. Proc Natl Acad Sci U S A 2005; 102:16569-72.

2. Huh S. Journal Article Tag Suite 1.0: National Information Standards Organization standard of journal extensible markup language. Sci Ed 2014;1:99-104.

3. Huh S. Coding practice of the Journal Article Tag Suite extensible markup language. Sci Ed 2014;1:105-12.

4. Jeong GH, Huh S. Increase in frequency of citation by SCIE journals of non-Medline journals after listing in an open access full-text database. Sci Ed 2014;1:24-6.

5. Huh S. Evidence of the internationalization of clinical endoscopy based on journal metrics. Clin Endosc 2015;48:317-21.

6. Huh S. How much progress has been made in journal metrics two years after the citation analysis of the Korean Journal of Urology? Korean J Urol 2015;56:276-9.

7. Huh S. What is the position of Clinical and Experimental Reproductive Medicine in its scholarly journal network based on journal metrics? Clin Exp Reprod Med 2014;41:147-50.

8. Huh S. How journal metrics illustrate the transformation of archives of plastic surgery into an international journal. Arch Plast Surg 2014;41:617-9.

9. Huh S. Journal metrics-based position of diabetes \& metabolism journal after the change of its text language to English. Diabetes Metab J 2014;38:187-93.

10. Huh S. How far has the international neurourology journal progressed since its transformation into an English language journal? Int Neurourol J 2014;18:3-9.

11. Huh S. How far has The Korean Journal of Internal Medicine advanced in terms of journal metrics? Korean J Intern Med 2013;28:635-8.

12. Huh S. Revision of the instructions to authors to require a structured abstract, digital object identifier of each reference, and author's voice recording may increase journal access. J Educ Eval Health Prof 2013;10:3.

13. Im J. Applying open researchers and contributors ID 
in scholarly journals. Sci Ed 2015;2:28-31.

14. Lammey R. CrossRef developments and initiatives: an update on services for the scholarly publishing com- munity from CrossRef. Sci Ed 2014;1:13-8.

15. Lammey R. CrossRef text and data mining services. Sci Ed 2015;2:22-7. 